\title{
Neuromuscular and skeletal adaptations to altered function in the orofacial region
}

\author{
James A. McNamara, Jr., D.D.S., Ph.D.
}

Ann Arbor, Mich.

$I_{t}$

has been difficult to explain the basic relationships between muscle function and bone growth. This problem has been explored extensively by biologists at the level of cellular tissue interaction and by clinicians evaluating the response of patients to the use of functional jaw orthopedies in orthodontic practice. The present study was undertaken in an attempt to answer the following and other significant questions relating to musculoskeletal interaction :

1. Can altered musele function direct bony changes?

2. Can skeletal changes result in altered muscle function?

3. Can changes in both skeletal and muscle patterns occur in conjunction with each other but without a direct cause-and-effect relationship?

4. If any of the above relationships exist, are the response thresholds related to age?

5. If changes are related to growth or age, can structural and functional relationships, once established, be altered?

Craniofacial disproportions were produced experimentally in rhesus monkeys (Macaca mulatta) at varying levels of maturation. The manner in which specific neuromuscular and skeletal adaptations oceur was then determined, using a variety of study methods, and the underlying remodeling and control processes associated with these responses were evaluated.

The effects of functional mandibular displacement were specifically assessed. A new occlusal configuration was devised which modified oral sensory stimuli,

From the Center for Human Growth and Development and the Department of Anatomy, The University of Michigan.

This study was supported in part by United States Public Health Service Grants DE02272 and DE-03610 and by USPHS Special Research Fellowship DE-43120.

This paper is part of a research project which won the Milo Hellman Research Award for 1973 and was presented before the American Association of Orthodontists in Dallas, Texas, in May, 1973. 
subsequently inducing anterior positioning of the mandible during functional jaw movements in rhesus monkeys at four defined stages of maturation. Specific skeletal, dental, and neuromuseular adaptations were studied and interrelated by means of serial electromyography, serial cephalometric radiography with metallic implants, and microscopic analysis.

\section{Review of the literature}

Investigators in the ficlds of orthodontics and orthopedics have long been interested in the relationship between form and function in the development of the growing child. Numerous studies have been undertaken, using different methods and producing widely varying results. Many human studies have centered around the treatment of the Class II malocclusion (distoclusion) with functional jaw orthopedic appliances. Although general agreement exists as to the basic effects of functional appliances on maxillary skeletal growth as well as on maxillary and mandibular dentoalveolar development, the actual nature of the response of the mandible is often obscured in clinical studies by difficulties in experimental design, treatment procedures, and measuring methods. A detailed review of the literature in this area is provided in another report. ${ }^{1}$

The effect of altered function on the growth of the mandible and of other craniofacial structures has been studied extcnsivcly in a scries of primate experiments. Various devices have been constructed which presumably necessitate the development of an altered functional position of the lower jaw. The craniofacial adaptations associated with the use of these devices have been studied either cephalometrically or histologically by a number of investigators. $^{2-11}$ In most instances dentitional alterations could be characterized by a change from a normal molar relationship (Class I) to a forward (mesial) relationship of the lower molars (Class IIT). This response seems similar in many respects to the correction of distoclusion mentioned previously.

In general, a Class III molar relationship experimentally produced by the functional anterior displacement of the mandible is a composite expression of a number of separate but interrelated adaptive processes. The inhibition of the normal downward and forward migratory pattern of the maxillary dentition and/or a mesial migration of the mandibular teeth can lead to this relationship. Second, skeletal adaptation may take place in which a change occurs in the direction and extent of growth at the head of the mandibular condyle which contributes to an opening rather than a closing of the gonial angle. The growth of the maxilla can likewise be redirected. Other skeletal adaptations may be observed throughout all parts of the craniofacial complex, including the cranial base.

The maturational level of the experimental animal seems to be of critical importance in an evaluation of the significance of the variables described above. Hiniker and Ramfjord ${ }^{\top}$ and Ramfjord and Enlow ${ }^{11}$ report that the temporomandibular joint in the adult animal is stable and resistant to occlusal change. In similar experiments using growing animals, however, significant adaptations are observed within this articulation. ${ }^{9}, 10$

Häupl and Psansky ${ }^{3}$ assume that the resultant change in the morphology of 
the craniofacial complex is due to the altered demands made by the musculature when it functions in a different position and orientation. Derichsweiler ${ }^{5}$ and Joho ${ }^{8}$ describe such an anterior positioning of the mandible as being of a "pure functional nature." However, the nature of the interaction between altered morphology (as produced by the appliance) and altered neuromuscular functional patterns is not clear. Similarly, the relationship between the neuromusculature and subsequent skeletal adaptations is not understood at present.

\section{Material and methods}

Sixty-four rhesus monkeys (Macaca mulatta) were studied: twenty-eight animals as the basic serial sample and thirty-six as supplemental histologic and/or electromyographic controls. In order to determine the relationships of age and maturation to musculoskeletal adaptations, the sample group of twenty eight animals was divided into four groups of seven animals according to stages of dentitional development.

The infant group (Group I) was characterized by the presence of a complete deciduous dentition at the onset of the study. The birth dates of the seven animals were known, and each animal was from 5 to 8 months of age. The juvenile animals (Group II) had complete deciduous dentitions, but the first permanent molars were also erupting or fully in ocelusion. The exact dates of birth of the animals in Groups II, III, and IV were not known. According to the tooth eruption scales of Hurme and Van Wagenen, ${ }^{12}$ the animals in Group II were approximately 18 to 24 months of age. The adolescent animals (Group III) possessed full permanent dentitions except for unerupted third molars and partially erupted canines. These animals were approximatcly 4 to $4 \frac{1}{2}$ years old. The adult monkeys (Group IV) had complete permanent dentitions, including fully erupted third molars, and they were approximately 6 to 7 years of age.

Each of the above groups consisted of three experimental and four control animals. The experimental animals were designated $a, b$, and $c$. Animals $d, e$, and $f$ represented cephalometric controls, and animal $g$ was used as both a cephalometric and a histologic control.

The duration of the experiment was 26 weeks. This period was divided into two equal segments: (1) a control period for collection of normal neuromuscular and skeletal data from all monkeys and (2) a subsequent period in which the growth data of the three experimental animals and the remaining four control animals from each group were compared. Thus, two types of control information were available: each experimental animal was compared to its own growth before experimentation as well as to the growth of the entire control group before and during experimentation.

\section{Radiographic procedures}

IMPLANTs. Twenty-nine tantalum implants ${ }^{13}$ were placed in each animal. Four pins were placed extraorally in the right side of the mandible, including one in the symphysis and one in the ramus near its posterior border. Five pairs of implants were inserted bilaterally in the maxillary region, and five 

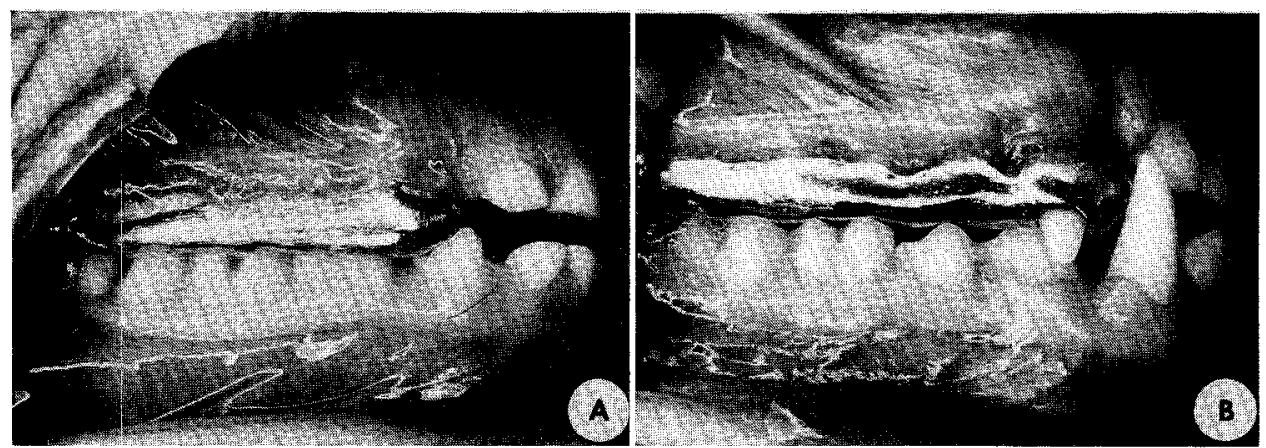

Fig. 1. Appliances. A, Infant. B, Adolescent.

implants were placed in the midline of the cranial base by penetrating the posterior pharyngeal wall. ${ }^{1}$ Ten implant pins were also inserted into other parts of the cranium, including three in the frontal bone.

CEPHALOMETRIC TECHNIQUE. Radiographs were taken at the beginning of the control period, at the beginning of the experimental period, and at the conclusion of the experiment. Additional radiographs were taken at other time intervals but were not analyzed in this study. Two exposures were made on each occasion-one with the teeth in occlusion and one with the mouth held open to allow for better radiographic visualization of the temporomandibular joint.

The radiographic methods used in this study have becn described in detail in earlier reports., 10,14 Industrial film was used in all cephalograms, as the grain of this film is very fine and permits precise definition of structures. Each film was enlarged three times on translite film. This procedure permits the tracing and measurement of very small inerements of growth that ordinarily would be illasked by errors in tracing.

Appliance construction. The intraoral appliances were gold castings which served to prompt all occlusal function $2 \mathrm{~mm}$. forward. Vertical displacement was also standardized at $2 \mathrm{~mm}$. After casts of the animal were mounted on an articulator, each appliance was carved in wax before casting to simulate a forward displacement of the maxillary occlusal anatomy. All buccal segments were covered by the appliance and connected by two transverse palatal bars (Fig. 1). After cementation, the appliance was earefully equilibrated to provide maximum occlusal contact and balance in the forward mandibular position.

Electromyographic procedures. Electromyographic recordings monitored neuromuscular function during the course of the experiment. During the initial 13-week control period, EMG recordings were made at monthly intervals to establish the base-line muscular pattern for each animal and to determine the limits of normal variation in these patterns. A total of five such recordings was taken, including one recording 4 days before cementation of the intraoral appliance and one at the time of cementation. This latter record was of importance because immediate reactions to the appliance could be monitored without altering any other experimental variable. A record was taken, continuously, for 1 hour immediately following cementation. Eight more records were obtained at suc- 
ceeding intervals of 6 hours, 1 day, 4 days, 1 week, 2 weeks, 4 weeks, 8 weeks, and during the twelfth week.

Initially, the monkey was anesthetized by an intramuscular injection of 6 to $10 \mathrm{mg} . / \mathrm{kg}$. of ketamine hydrochloride. Ketamine is a short-acting, dissociative anesthetic which has only a minor and transient effect upon the musculature of the orofacial region. ${ }^{1 b}$ The anesthetized monkey was then placed in a soundproof, electrically shielded chamber and seated in a restraining device designed for electromyographic procedures on nonhuman primates. ${ }^{16}$ The head of the animal was oriented in a fixed position by means of a Plexiglas head holder to allow for normal jaw function in an unanesthetized condition.

Bipolar needle electrodes were inserted into the anterior temporal, posterior temporal, orbicularis oris, and suprahyoid muscles. The suprahyoid group, consisting of the anterior digastric, mylohyoid, and geniohyoid muscles, was regarded as a single muscle group because of the difficulty in separating the muscles anatomically during electrode placement. ${ }^{1}$ To monitor the lateral pterygoid, two $25 \mathrm{~mm}$. Teflon-insulated needle electrodes were passed extraorally through the sigmoid notch into the superior lateral pterygoid head. ${ }^{1,}{ }^{17}$ I have reported separate and independent functions for each head of the lateral pterygoid muscle. All recordings were obtained from the musculature on the left side.

After verification of electrode placement, the animal was left isolated in the soundproof room for a minimum of 30 additional minutes to allow for complete recovery from the anesthetic. After this time, recordings of posture, oral reflexes, and random jaw movements were initiated while the animal was still in isolation. Reflex salivary swallows were recorded at this time. Later, the investigator entered the soundproof room and generated water swallows and subsequent clearing swallows by the administration of 0.5 c.c. tap water through a syringe into the animal's mouth. Chewing was elicited by feeding the animal small chunks of sugar and bits of apple.

Postural activity is recorded when all of the muscles involved in mandibular movement demonstrate no other activity than that which is necessary to hold the mandible in a balanced position against gravity. Gravitational forces evoke constant asynchronous motor discharges in the antigravity muscles which result in a mild state of contraction or tension in these muscles. ${ }^{1,}{ }^{18}$ In this report, the muscle activity associated with the maintenance of the postural ("rest") position of the mandible has been used as an indicator of the response of the musculature to the experimental conditions. In addition, a general discussion of muscle activity during functional movements is presented. Howcver, spceific and detailed discussions of the effects of the experiment on mastication and deglutition are found elsewhere. ${ }^{1}$

Histologic procedures. At the conclusion of the experimental period, the gold onlays were removed from all twelve experimental animals and the final set of radiographs and intraoral photographs was taken. Then animals $b$ and $c$ and control animal $g$ from each group were killed by saline and phosphate buffered formalin perfusion. The temporomandibular joint on the right side and its surrounding tissues were removed and placed in formalin. The tissue block was later decalcified in formic acid, embedded in celloidin, and, finally, serially sectioned 
parallel to the sagittal plane at 10 to 20 microns. Three of every ten sections were stained alternatively with hematoxylin and eosin, Masson's, and modified Mallory stains. A fourth section was mounted unstained.

\section{Findings}

Neuromusculature. The results obtained during the experimental period were most easily grouped into three phases: Phase 1, which included the initial reactions of the animal during the first 6 hours of the experiment; Phase 2, which included records from 1 day through 1 week; and Phase 3, which included the second week through the end of the experiment. Alterations in patterns of muscle function during the experimental period were compared with the control patterns. Since variations were noted among animals, even of the same age group, each experinental aninal was used as his own control and a range of normal function was determined for each of them during the first 13 weeks of the project.

PHASE 1 (FIRST 6 HOURS OF THE EXPERIMENT). Cementation of the appliance on the maxillary arch altered the oral environment, and immediate, varied responses resulted. In general, periods of hyperactivity and hypoactivity could be observed in the same animal (Fig. 2). The animal closed its mouth on the appliance in erratic biting and clenching movements, as if searching for a place to establish a comfortable occlusal position. The normal functional patterns were distorted and disrupted, and a loss of muscular synchrony was observed in half of the animals. Exaggerated random jaw movements were common. The infant and juvenile monkeys demonstrated postural activity primarily in the temporal muscle, as they did during the control period. However, several of the older animals developed a pronounced dominance of masseter function in posture as well as during functional movements.

One of the most significant changes in activity during the first hours was observed in the suprahyoid muscle group. Hypertonic discharges from the suprahyoids were observed in all age groups. It was assumed that this activity helped to lower the postural position of the mandible. The mandible was observed to be carried inferiorly during this time, so that the lower teeth would not oppose the appliance. This hypertonicity was not continuous, however, because periods of normal activity were also noted when the mandible was observed to be in its usual orientation.

By the end of 6 hours, only one of the twelve animals (monkey IVb) had attained any significant alteration in the anteroposterior position of the mandible. It was noted that the mandible of this animal was carried slightly forward from its original position, and increased firing of the superior head of the lateral pterygoid was recorded. Alterations in the function of the inferior head of this muscle were not specifically examined during the experimental period, although recordings from this head of the lateral pterygoid were often obtained during attempts at electrode placement within the superior head. Such recordings from the inferior head indicated that no increased activity was present in this head during the first 6 hours of the experiment.

PHASE 2 (1 DAY THROUGH 1 WEEK). This period was characterized by the re- 

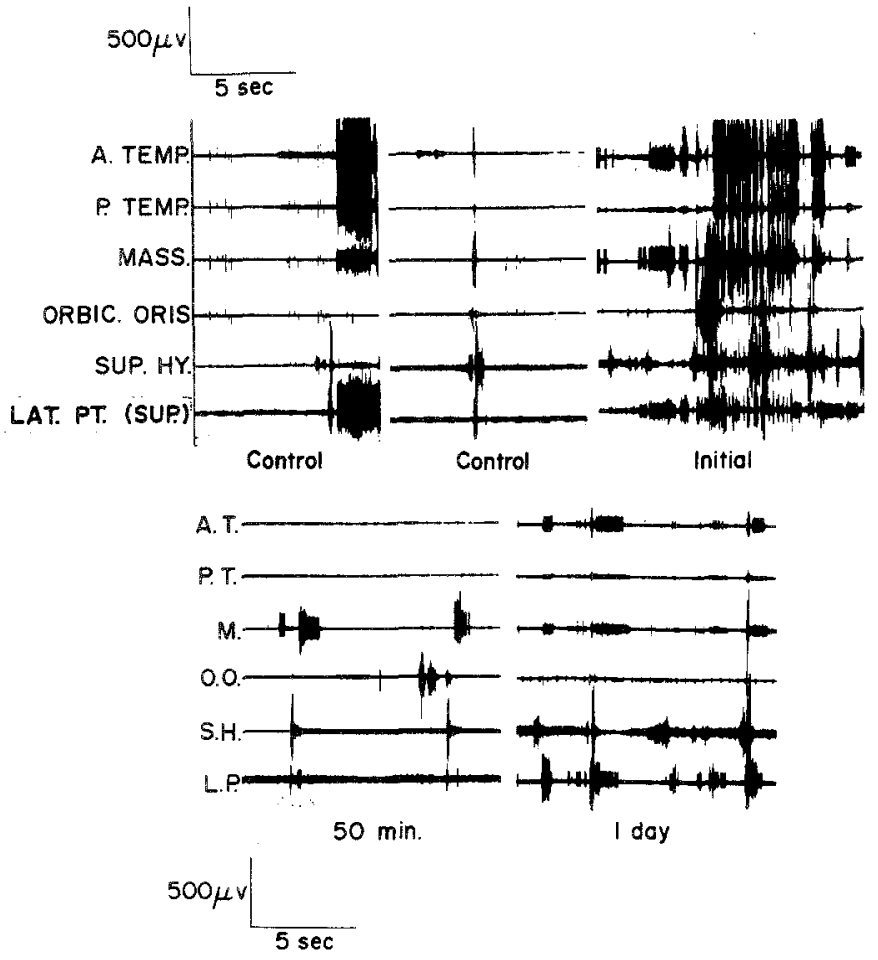

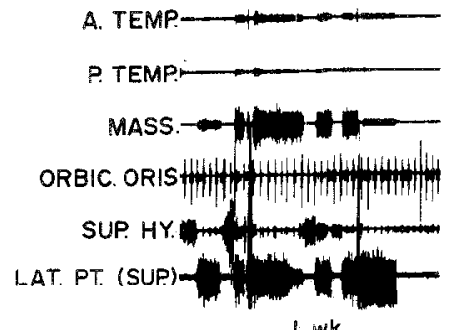

1. wh.
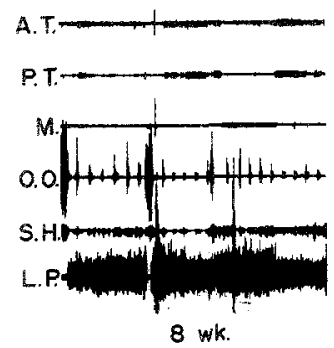

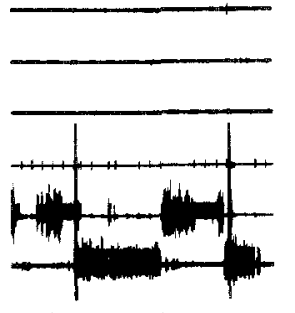

4 wk.

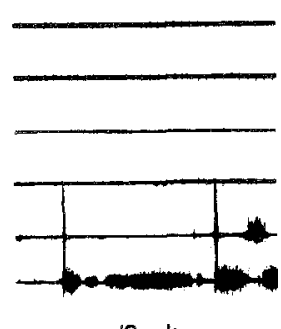

12 wk.

Fig. 2. Overview of typical muscle activity during the experimental period. In the control records, note the synergistic function of the elevators and superior head of the lateral pterygoid muscle during such functional movements as clenching and swallowing. Initially, coordinated muscle function was disrupted. By one week, the amplitude of the lateral pterygoid activity is observed not only during movement but also during postural maintenance. This activity reaches a maximum at 8 weeks and then becomes reduced by the end of the experimental period (animal la). (Recording speed, $5 \mathrm{~mm}$. per second.) 
establishment of oral functions and by modifications of the adaptive response observed during the first 6 hours of the experiment. Jaw movements during this time were not as strong or as dramatic as the biting, the clenching, and the exaggerated mandibular excursions which occurred during Phase 1.

The hypertonicity of the suprahyoid muscles, which presumably had assisted in keeping the lower jaw depressed and away from the appliance, gradually disappeared in all the animals by the end of the first week. The anterior temporal and masseter were dominant in postural recordings. In two of the younger and all but one of the more mature animals, a generalized increase was evident in the postural firings of the elevators, including the posterior temporal. However, there was a decrease in the activity of the posterior temporal in three of the younger animals. Tonic discharges from the superior head of the lateral pterygoid were also observed during posture in some of the animals, but the occasional recordings from the inferior head (which were mentioned earlier) revealed no indication of increased activity in this portion of the lateral pterygoid during the first week.

PHASE 3 (2 WEEKS THROUGH THE END OF THE EXPERIMENT). The anterior portion of the temporal muscle gradually reassumed the most active role during posture. In the earlier periods, the masseter had been significant in the maintenance of the postural position of the mandible, but presumably, as the various orofacial tissue systems adapted to the appliance, this muscle gradually assumed a less important role in posture. In four of the aninals (one infant, two juveniles, and one adult), however, there was a marked decrease in the postural activity instear of a return to normal function. This decrease persisted throughout the experimental period.

The most pronounced adaptation observed electromyographically during Phase 3 occurred in the function of the superior head of the lateral pterygoid muscle. In the control recordings, superior head activity was associated mainly with clevator function; only a few random spikes from individual motor units were observable in postural records. By the end of 2 weeks, tonic discharges from the superior head of the lateral pterygoid were observed in half of the animals. These discharges, for the most part, preceded or followed functional activities, such as the swallow and random jaw movement (Fig. 2). During this time the superior head often fired alone, without concurrent activity in any of the monitored muscle groups.

At 4 weeks, all but one of the experimental animals had tonic firings in the superior head during posture and during functional movements (Fig. 2). By 8 weeks, this activity had increased in three animals and had decreased in four animals. In the last records of the experimental period, which were taken during the twelfth week, firings of the superior portion of the lateral pterygoid had disappeared in two animals and continued at a reduced level in eight others (Fig. 2). Even at the maximum level of activity, the tonic firings from the superior head were not evident in all the recordings of a single session. During periods of little or no jaw movement, particularly in initial postural recordings, this response was not observed in all instances, indicating that the reflexive forward positioning of the mandible was not continuous. 


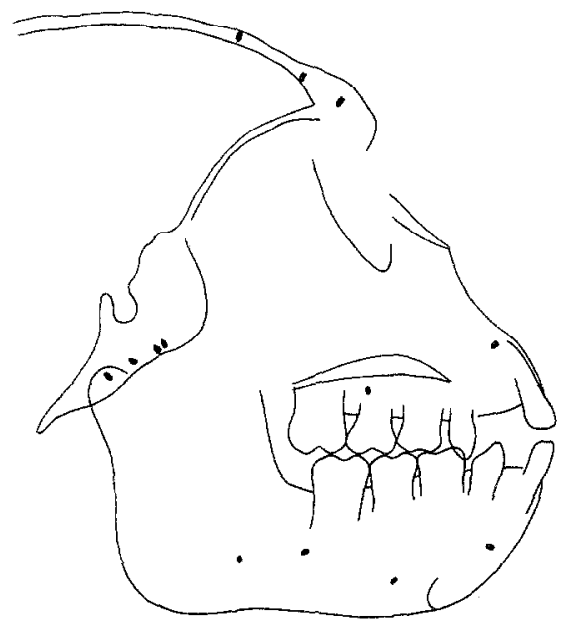

Fig. 3. Cephalometric tracing of a juvenile animal immediately after appliance removal.

Surprisingly, the occasional recordings from the inferior head of the lateral pterygoid did not indicate that this head of the muscle was hyperactive. The inferior head continued to function synergistically with the suprahyoid museulature but demonstrated no increase in activity during postural maintenance or functional movements.

Macroscopic skeletal growth and adaptation. At the conclusion of the 13 -week experimental period, both skeletal and dental adaptations were observed and analyzed in every experimental animal. These adaptations were due to the alterations in the oral environment and the subsequent changes in function. Ten of the twelve monkeys demonstrated an anteroposterior alteration in the relationship of the mandibular and maxillary buccal segments (Fig. 3). The nature and extent of the specific adaptive modifications varied among age groups and varied to a lesser extent among the individual animals in each group.

STATISTICAL ANALYSIS. The cephalometric data collected in this experiment are inherently multivariate. Many different but nonindependent measures were observed for each animal. In analyzing this type of data, multivariate procedures which take into account the correlation structure of the data should normally be employed. Unfortunately, the small sample size within each age group made the use of such procedures impossible. As an alternative, two different univariate procedures were employed. The use of these two methods arises from the fact that two types of controls were incorporated in the experimental design.

In the first procedure, a $t$ statistic was computed for every variable in each age group to test the null hypothesis that the change observed during Period II (the experimental period) was equal to the change observed in Period I (the control period). This procedure was carried out separately for the experimental and control groups. Results for the experimental groups are reported in Tables I, II, and III. The null hypothesis was rejected at the 5 per cent level (using a one-tailed procedure) for eighteen variable age group combinations in the experimental groups and for three combinations in the control groups. 
Table I. Mandibular skeletal growth of experimental animals during Period I (the control period) and Period II (the experimental period)

\begin{tabular}{|c|c|c|c|c|c|c|c|c|}
\hline \multirow[b]{2}{*}{ Measures } & \multicolumn{2}{|c|}{ Period I } & \multicolumn{2}{|c|}{ Period II } & \multicolumn{2}{|c|}{ Mean difference } & \multirow{2}{*}{$\begin{array}{c}t \\
\text { stat. }\end{array}$} & \multirow{2}{*}{$\begin{array}{l}\text { Signifi- } \\
\text { cance }\end{array}$} \\
\hline & $\bar{x}$ & S.D. & $\bar{x}$ & S.D. & $\bar{x}$ & S.D. & & \\
\hline & \multicolumn{8}{|c|}{ Group $I$} \\
\hline Condylion & $3.24 \mathrm{~mm}$. & $0.44 \mathrm{~mm}$. & $3.61 \mathrm{~mm}$. & $0.99 \mathrm{~mm}$. & $0.37 \mathrm{~mm}$. & $0.59 \mathrm{~mm}$ & 1.087 & \\
\hline Superior condyle & 2.35 & 0.79 & 1.95 & 1.06 & -0.40 & 0.89 & -0.778 & \\
\hline Posterior condyle & 2.29 & 0.13 & 3.06 & 0.37 & 0.77 & 0.35 & 3.887 & $0.03^{* * *}$ \\
\hline Anterior border & -0.68 & 0.24 & -0.54 & 0.29 & -0.14 & 0.11 & -2.167 & \\
\hline Posterior border & 2.28 & 0.53 & 2.34 & 0.84 & 0.06 & 0.32 & 0.363 & \\
\hline \multirow[t]{2}{*}{ CRO angle } & $-3.1^{\circ}$ & $4.4^{\circ}$ & $2.4^{\circ}$ & $3.1^{\circ}$ & $5.5^{\circ}$ & $1.0^{\circ}$ & 6.995 & $0.01 *$ \\
\hline & \multicolumn{8}{|c|}{ Group 11} \\
\hline Condylion & $1.94 \mathrm{~mm}$. & $0.51 \mathrm{~mm}$. & $2.94 \mathrm{~mm}$. & $0.51 \mathrm{~mm}$. & $1.00 \mathrm{~mm}$. & $0.11 \mathrm{~mm}$. & 16.455 & $0.002^{*}$ \\
\hline Superior condyle & 1.15 & 0.39 & 1.56 & 0.29 & 0.41 & 0.11 & 6.556 & 0.01 \\
\hline Posterior condyle & 1.81 & 0.37 & 2.24 & 0.38 & 0.43 & 0.30 & 2.469 & $0.07^{*}$ \\
\hline Anterior border & -0.72 & 0.31 & -0.87 & 0.22 & -0.15 & 0.51 & -0.489 & \\
\hline Posterior border & 1.48 & 0.60 & 1.74 & 0.15 & 0.26 & 0.46 & 0.985 & \\
\hline \multirow[t]{2}{*}{ CRO angle } & $-1.1^{\circ}$ & $1.6^{\circ}$ & $1.5^{\circ}$ & $1.5^{\circ}$ & $2.6^{\circ}$ & $0.3^{\circ}$ & 1.579 & * \\
\hline & \multicolumn{8}{|c|}{ Group III } \\
\hline Condylion & $1.33 \mathrm{~mm}$. & $0.16 \mathrm{~mm}$ & $0.92 \mathrm{~mm}$. & $0.93 \mathrm{~mm}$ & $-0.41 \mathrm{~mm}$ & $0.77 \mathrm{~mm}$ & -0.445 & \\
\hline Superior condyle & 0.88 & 0.46 & 0.51 & 0.70 & -0.37 & 1.35 & -0.681 & \\
\hline Posterior condyle & 1.21 & 0.85 & 0.87 & 0.47 & -0.34 & 0.53 & -0.383 & \\
\hline Anterior border & -0.41 & 0.40 & -0.40 & 0.36 & 0.01 & 0.69 & 0.980 & \\
\hline Posterior border & 0.62 & 0.63 & 0.50 & 0.41 & -0.12 & 0.24 & -0.480 & \\
\hline \multirow[t]{2}{*}{ CRO anglo } & $0.6^{\circ}$ & $1.4^{\circ}$ & $0.8^{\circ}$ & $1.0^{\circ}$ & $0.2^{\circ}$ & $0.1^{\circ}$ & 0.745 & \\
\hline & \multicolumn{8}{|c|}{ Group IV } \\
\hline Condylion & $0.24 \mathrm{~mm}$. & $0.41 \mathrm{~mm}$. & $0.38 \mathrm{~mm}$. & $0.45 \mathrm{~mm}$ & $0.14 \mathrm{~mm}$. & $0.04 \mathrm{~mm}$ & 5.735 & .01 \\
\hline Superior condyle & 0.20 & 0.35 & 0.28 & 0.28 & 0.08 & 0.17 & 0.829 & \\
\hline Posterior condyle & 0.44 & 0.38 & 0.23 & 0.28 & -0.21 & 0.11 & -3.295 & \\
\hline Anterior border & -0.07 & 0.07 & -0.29 & 0.27 & 0.22 & 0.20 & 1.889 & \\
\hline Posterior border & 0.21 & 0.12 & 0.12 & 0.27 & -0.09 & 0.37 & -0.419 & \\
\hline CRO angle & $0.6^{\circ}$ & $0.1^{\circ}$ & $0.1^{\circ}$ & $0.6^{\circ}$ & $-0.5^{\circ}$ & $0.1^{\circ}$ & -0.762 & \\
\hline
\end{tabular}

Statistics compiled for three animals per group.

${ }^{*}$ Also statistically significant from control group at 0.05 level.

***Also statistically significant from control group at 0.005 level.

In the second procedure, a t statistic was computed for every variable in each age group to test the null hypothesis that the mean change value in the experimental group was equal to that of the control group. This was done separately for each time period. During Period I, the null hypothesis was rejected for four variable age group combinations. In Period II, after the experimental treatment had been administered, the null hypothesis was rejected for twenty-five combinations. The variables for which this occurred are indicated in Tables I, II, and III by asterisks in the rightmost column.

MANDIBULAR ADAPTATIONs. Two general morphologic alterations were observed in the mandible: (1) changes in the growth pattern of the condylar head and 

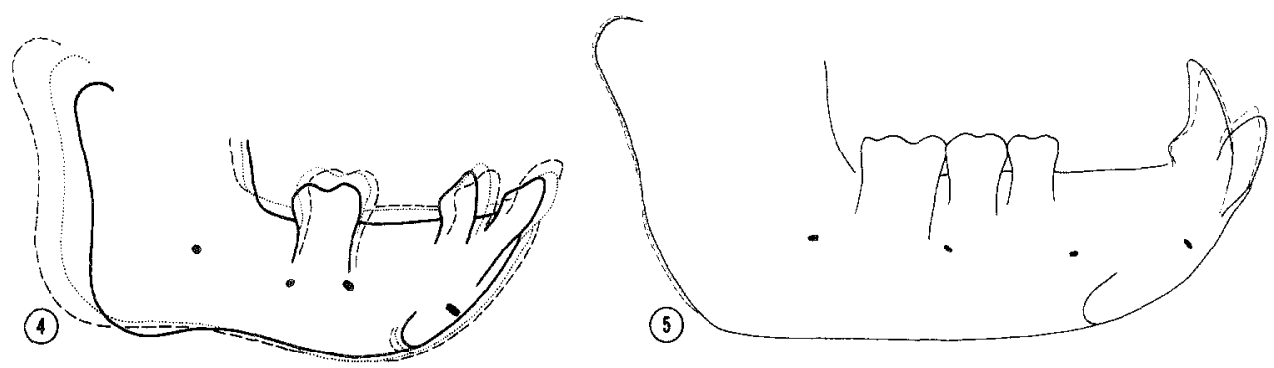

Fig. 4. Growth of the mandible in an infant experimental animal (la) during the control and experimental periods. In all tracings, the solid line indicates the beginning of the control period, the dotted line indicates the beginning of the experimental period, and the dashed line indicates the end of the experiment. Note the inhibition of vertical drifting of the deciduous molar and the compensatory migration of the incisor. The increment of growth along the posterior surface of the condyle increased significantly during the experimental period.

Fig. 5. Growth of the mandible in an adult experimental animal (IVb) during the control and experimental periods. Note the forward and downward tipping of the canines and the compensatory movement of the incisors. In this animal, the buccal segments were stable.

(2) compensatory migration of the dentition. The relative significance of these changes depended in part upon the age of the animal.

THE CONDYLAR REGION. Increases in the extent of growth at the condyle were most pronounced in Groups I and II. The average rates of posterior, superior, and posterosuperior growth at the head of the condyle in the juvenile experimental animals were statistically significant from control level values. For example, the average growth increment of the experimental juvenile animals measured at condylion during the experimental period was determined to have been 51 per cent greater than the average increment of the same animals during the control period (Table I). The exact percentage increase varied with the individual animal. The lowest increase in condylar growth was 36 per cent in animal II $a$. Animal II $c$ had the highest increase ( 74 per cent). The average growth at condylion in the experimental animals during Pcriod II was 27 to 38 per cent greater than that of the control animals during a similar time interval. The rate of posterior condylar growth in the experimental infant animals was also significantly greater than control level values during Period II (Table I).

A negligible increase in posterosuperior growth of the condyle was noted in the ddult animals, and a slight average decrease in the rate of condylar growth was observed in Group III (Table I). Two of the monkeys (III $a$ and III $c$ ) experienced much difficulty in functional adaptation to the appliance, as evidenced by a weight loss of 1.5 kilograms and 0.8 kilogram, respectively, during the first 4 weeks. Although this body weight was regained by the end of the experiment, a reduction in over-all skeletal growth rate may have occurred in these animals.

A change in the direction of growth at the condyle may have a similar effect on mandibular position, as does an increase in growth increment. During the control period, infant monkeys had a high vertical component of condylar 
growth. During the experimental period, however, lhere was an alteration in the direction of condylar growth in all three infant animals. The rate of superior condylar growth decreased, whereas the rate of posterior growth increased (Fig. 4). In this young age group, which had the highest over-all rate of normal growtl, a change in the vector of condylar growth reoriented the growth of the mandible in a more forward direction.

Because both superior and posterior apposition increased during Period II, vectoral changes were less evident in the juvenile animals. Condylar growth became slightly more horizontal in two of the adolescent animals, although in animal III $a$ this change in ratio resulted from a decrease in rate of superior condylar growth rather than an increase posteriorly. Vectoral changes at the condyle were not evident in the adult monkeys.

Adaptive responses in the condylar region thus were most evident in the two younger age groups. The extent of growth was significantly increased in Groups I and IT. The direction of condylar growth was also altered, primarily in the infant animals. Growth at the condyle in the two older age groups was not significantly affected by the experiment.

THE MANDIBULAR RAMUS. 'The growth of the mandibular ramus measured at the level of intersection with the occlusal plane was not altered in any of the age groups. No significant increase was noted in the rate of bone deposition along the posterior border of the ramus (Table I). In the younger experimental monkeys, however, the observed alterations in condylar growth affected the angle of the ramus and the condyle to the occlusal plane. In the untreated infant animals, the condylar-ramus-occlusal (CRO) angle usually closes by 3 to 4 degrees during a 13-week interval. Yet, during Period II, a reversal of this trend was observed in the experimental animals as the angle opened an average of 2 to 3 degrees. Since closure would normally have occurred, the net change was approximately 5 to 7 degrees, a statistically significant increase (Table I). A similar pattern was observed in Group II, but the CRO angle was unaffected in the two older age groups.

THE MANDIBULAR DENTITION. Skeletal adaptations in the mandible were limited primarily to the infant and juvenile animals. In constrast, dentitional adjustments were more pronounced in the more pronounced mature age groups (Table II). Dentitional adaptations were analyzed with regard to the normal migration of the dentition at each age, since tooth movement which occurred during Period II could also have been related to patterns of normal growth as well as to the conditions of the experiment.

Buccal segments: Of principal concern were adaptations in the mandibular buccal segments, for an apparent change in intermaxillary relationship could occur by an experimentally induced mesial migration of the lower molars. Mesial movement of the lower buceal segments which could be attributed to the appliances occurred only in specific animals of Groups II, III, and IV. For example, animal IIc had an induced molar migration of $0.5 \mathrm{~mm}$. mesially, while the other two monkeys in that group had no appreciable alteration in drift pattern. Three of the six adolescent and adult animals had mesial movement of the buccal segments. Since forward migration is usually minimal at these maturation 
Table II. Mandibular dental changes in the experimental animals during Period 1 and Period II

\begin{tabular}{|c|c|c|c|c|c|c|c|c|}
\hline \multirow[b]{2}{*}{ Measures } & \multicolumn{2}{|c|}{ Period I } & \multicolumn{2}{|c|}{ Period II } & \multicolumn{2}{|c|}{$\begin{array}{c}\text { Mean } \\
\text { difference }\end{array}$} & \multirow[b]{2}{*}{$\begin{array}{c}t \\
\text { stat. }\end{array}$} & \multirow[b]{2}{*}{$\begin{array}{l}\text { Signifi- } \\
\text { cance }\end{array}$} \\
\hline & $\left.\begin{array}{c}\bar{x} \\
(m m .)\end{array}\right)$ & $\begin{array}{c}\text { S.D. } \\
(m m .)\end{array}$ & $\begin{array}{c}\vec{x} \\
(m m .)\end{array}$ & $\begin{array}{c}S . D . \\
(m m .)\end{array}$ & $\begin{array}{c}\bar{x} \\
(m m .)\end{array}$ & $\begin{array}{c}S . D . \\
(m m .)\end{array}$ & & \\
\hline & \multicolumn{8}{|c|}{ Group $I$} \\
\hline Incisor horizontal & 1.03 & 0.29 & 0.22 & 0.29 & 0.81 & 0.59 & 24.000 & 0.001 \\
\hline Incisor vertical & 0.34 & 0.28 & 0.71 & 0.44 & 0.37 & 0.54 & 1.184 & \\
\hline Canine horizontal & 0.79 & 0.18 & 0.68 & 0.36 & -0.11 & 0.20 & -0.985 & \\
\hline Canine vertical & 0.41 & 0.25 & -0.14 & 0.35 & -0.55 & 0.59 & -1.592 & $* *$ \\
\hline Deciduous molar horizontal & 0.47 & 0.20 & 0.60 & 0.32 & 0.13 & 0.15 & 1.511 & \\
\hline \multirow[t]{2}{*}{ Deciduous molar vertical } & 0.72 & 0.48 & 0.23 & 0.20 & -0.49 & 0.67 & -1.276 & * \\
\hline & \multicolumn{8}{|c|}{ Group $I I$} \\
\hline Incisor horizontal & 0.68 & 0.58 & 0.33 & 0.37 & -0.35 & 0.79 & -0.755 & \\
\hline Incisor vertical & 0.09 & 0.05 & 0.87 & 0.16 & 0.76 & 0.21 & 6.506 & $0.01^{*}$ \\
\hline Canine horizontal & 0.50 & 0.23 & 0.52 & 0.21 & 0.02 & 0.33 & 0.869 & * \\
\hline Canine vertical & 0.27 & 0.09 & 0.04 & 0.24 & -0.23 & 0.32 & -1.118 & \\
\hline First molar horizontal & 0.33 & 0.15 & 0.48 & 0.35 & 0.15 & 0.41 & 0.635 & \\
\hline \multirow[t]{2}{*}{ First molar vertical } & 0.27 & 0.23 & 0.32 & 0.37 & 0.05 & 0.30 & 0.327 & \\
\hline & \multicolumn{8}{|c|}{ Group $I I I$} \\
\hline Incisor horizontal & 0.55 & 0.04 & 0.39 & 1.26 & -0.16 & 1.24 & -0.225 & \\
\hline Incisor vertical & 0.00 & 0.00 & 0.74 & 0.54 & 0.74 & 0.54 & 2.369 & $0.07^{*}$ \\
\hline Canine horizontal & 0.92 & 0.30 & 1.17 & 0.06 & 0.25 & 0.34 & 1.236 & \\
\hline Canine vertical & 0.97 & 1.20 & -0.44 & 0.30 & -1.41 & 1.37 & -1.782 & \\
\hline First molar horizontal & 0.09 & 0.13 & 0.44 & 0.28 & 0.35 & 0.19 & 3.228 & $0.04^{* *}$ \\
\hline First molar vertical & 0.07 & 0.12 & -0.03 & 0.17 & -0.10 & 0.11 & -1.686 & $x:$ \\
\hline Second molar horizontal & 0.18 & 0.17 & 0.38 & 0.22 & 0.20 & 0.42 & 8.488 & $0.02^{* *}$ \\
\hline \multirow[t]{2}{*}{ Second molar vertical } & 0.08 & 0.13 & -0.19 & 0.17 & -0.27 & 0.58 & 8.000 & $0.01 * *$ \\
\hline & \multicolumn{8}{|c|}{ Group IV } \\
\hline Incisor horizontal & 0.14 & 0.20 & -0.26 & 0.27 & -0.40 & 0.36 & -1.939 & 0.10 \\
\hline Incisor vertical & 0.00 & 0.00 & 0.63 & 0.04 & 0.63 & 0.10 & 10.539 & $0.005 \%$ \\
\hline Canine horizontal & 0.07 & 0.06 & 0.62 & 0.40 & 0.55 & 0.45 & 2.120 & $0.08 \%$ \\
\hline Canine vertical & 0.00 & 0.00 & -1.07 & 0.34 & -1.07 & 0.34 & 5.461 & $0.02 * *$ \\
\hline First molar horizontal & 0.00 & 0.00 & 0.17 & 0.29 & 0.17 & 0.29 & 1.000 & \\
\hline First molar vertical & 0.01 & 0.02 & 0.12 & 0.32 & 0.11 & 0.31 & 0.589 & \\
\hline Second molar horizontal & 0.00 & 0.00 & 0.16 & 0.34 & 0.16 & 0.34 & 0.825 & \\
\hline Second molar vertical & 0.00 & 0.00 & 0.11 & 0.44 & 0.11 & 0.44 & 0.433 & \\
\hline Third molar horizontal & 0.00 & 0.00 & 0.09 & 0.22 & 0.09 & 0.22 & 0.730 & \\
\hline Third molar vertical & -0.04 & 0.03 & -0.11 & 0.10 & -0.07 & 0.67 & -1.857 & \\
\hline
\end{tabular}

Statisties compiled for three animals per group.

*Also statistically significant from control group at 0.05 level.

**Also stetistienlly significant from control group at 0.01 level.

**Also statistically significant from control group at 0.005 level.

levels, much of this movement was interpreted as having been experimentally induced. In contrast, the horizontal movement of the buccal segments of the infant group was not statistically significant from control level values (Table II). Only in one adult animal ( IVa) was the resultant change in molar relationship due primarily to an experimentally induced mesial migration of the lower buccal segments. 

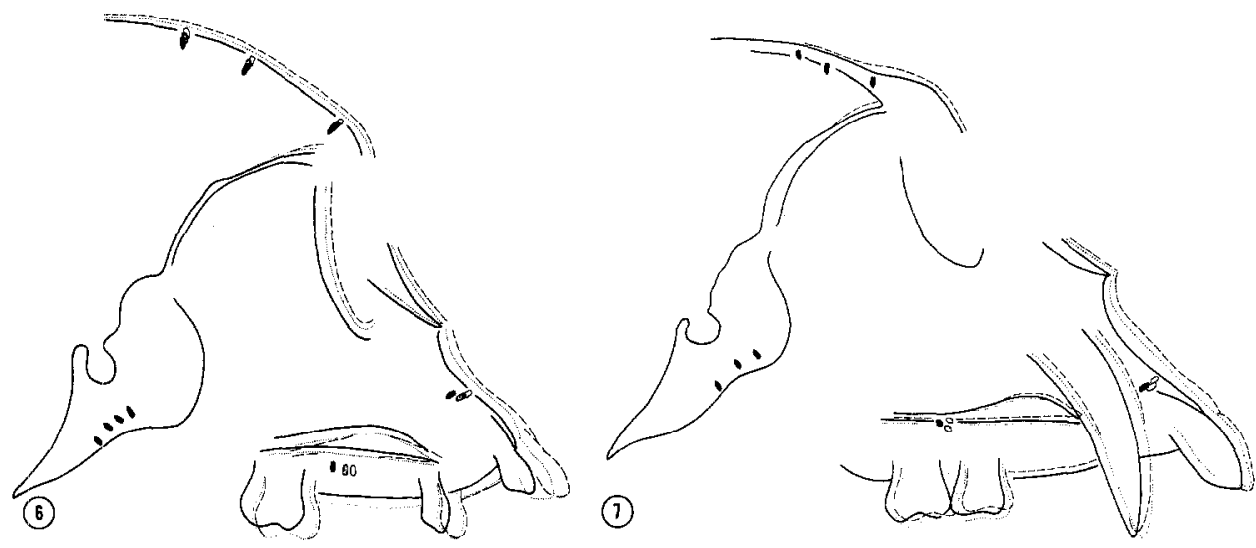

Fig. 6. Growth of the maxillary complex in a juvenile experimental animal (IIb) during the control and experimental periods. Note the alteration of the vector of maxillary growth as indicated by the movements of the premaxillary and maxillary implants. The solid implant indicates the position at the beginning of the control period, the stippled implant indicates the beginning of the experimental period, and the outlined implant indicates the end of the experimental period. Note also the effective decrease in the forward and downward migration of the maxillary canine and molar during the experimental period.

Fig. 7. Growth of the maxillary complex in an adolescent experimental animal (IIla). Note the slight superior displacement of the maxillary complex during the experimental period, as indicated by the movement of the maxillary and premaxillary implants.

Canines: More significant modifications in dentitional position were observed anteriorly, particularly in the adolescent and adult monkeys (Table II). During the control period, the lower canines in the control animals erupt and drift in a forward and upward direction. In adapting to the appliance, the permanent canines of Groups III and IV were tipped forward and downward to accommodate the bulk of the appliance between the upper and lower canines. Through tipping of the canines, it was then possible to carry the mandible in a relatively normal anteroposterior position (Fig. 5). This occurred in animal IIIc and possibly in animal IVb.

In contrast to the older animals, the infants and juveniles had no appreciable increase in the forward migration of the canine teeth. However, a slight decrease in vertical height was noted, primarily due to occlusal and distal abrasion of the relatively soft deciduous canines.

Incisors: The incisors of all animals adapted in the same manner. The normal anteroposterior pattern of migration was altered, so that vertical migration increased while forward migration was inhibited (Figs. 4. and 5, Table II). This pattern of incisor movement was due in part to the $2 \mathrm{~mm}$. increase in vertical dimension caused by the appliance. The lower incisors drifted to close the space and occlude with their dental antagonists.

ADAPTATIONS IN THE MAXILlary COMPLEX. Specific skeletal and dental adaptations were also observed in the maxillary region of each age group. Any inhibition of the effective forward and downward movement of the maxillary complex assisted in the production of a Class III molar relationship. Increased growth 
Table III. Displacement of the maxillary complex in the experimental animals during Period I and Period II

\begin{tabular}{|c|c|c|c|c|c|c|c|c|}
\hline \multirow[b]{2}{*}{ Measures } & \multicolumn{2}{|c|}{ Period $I$} & \multicolumn{2}{|c|}{ Period II } & \multicolumn{2}{|c|}{$\begin{array}{c}\text { Mean } \\
\text { difference }\end{array}$} & \multirow[b]{2}{*}{$\begin{array}{c}t \\
\text { stat. }\end{array}$} & \multirow[b]{2}{*}{$\begin{array}{c}\text { Signifit } \\
\text { cance }\end{array}$} \\
\hline & $\begin{array}{c}\bar{x} \\
(m m .)\end{array}$ & $\left|\begin{array}{c}S . D . \\
(m m .)\end{array}\right|$ & $\begin{array}{c}\bar{x} \\
(m m .)\end{array}$ & $\begin{array}{c}\text { S.D. } \\
(m m .)\end{array}$ & $\begin{array}{c}\bar{x} \\
(m m .)\end{array}$ & $\left|\begin{array}{c}\text { S.D. } \\
(m m .\end{array}\right|$ & & \\
\hline & \multicolumn{8}{|c|}{ Group $I$} \\
\hline Premaxillary implant horizontal & 1.68 & 0.40 & 1.54 & 0.38 & -0.14 & 0.31 & -0.787 & \\
\hline Premaxillary implant vertical & 0.28 & 0.43 & -0.04 & 0.52 & -0.32 & 0.56 & -0.360 & \\
\hline Maxillary implant horizontal & 1.28 & 0.49 & 2.06 & 0.63 & 0.78 & 1.16 & 1.163 & \\
\hline Maxillary implant vertical & 0.83 & 0.44 & 0.41 & 0.71 & -0.42 & 0.41 & -1.531 & \\
\hline \multirow[t]{2}{*}{ Palatal descent } & 0.43 & 0.20 & 0.50 & 0.71 & 0.07 & 0.81 & 0.072 & \\
\hline & \multicolumn{8}{|c|}{ Group II } \\
\hline Premaxillary implant horizontal & 1.40 & 0.38 & 1.09 & 0.88 & -0.31 & 0.51 & -0.860 & \\
\hline Premaxillary implant vertical & 0.05 & 0.07 & -0.56 & 0.13 & -0.61 & 0.59 & -14.600 & $0.02^{* *}$ \\
\hline Maxillary implant horizontal & 1.61 & 0.22 & 1.44 & 0.97 & -0.17 & 1.07 & -0.269 & \\
\hline Maxillary implant vertical & 0.22 & 0.23 & 0.07 & 0.21 & -0.15 & 0.43 & -0.619 & \\
\hline \multirow[t]{2}{*}{ Palatal descent } & 0.37 & 0.16 & -0.35 & 0.18 & -0.72 & 0.24 & -5.127 & $0.02 * *$ \\
\hline & \multicolumn{8}{|c|}{ Group $I I I$} \\
\hline Premaxillary implant horizontal & 0.68 & 0.59 & 0.80 & 0.55 & 0.12 & 0.72 & 0.293 & \\
\hline Premaxillary implant vertical & -0.13 & 0.26 & -0.79 & 0.17 & -0.66 & 0.25 & -4.567 & $0.02^{* * *}$ \\
\hline Maxillary implant horizontal & 0.53 & 0.69 & 0.82 & 0.77 & 0.29 & 1.07 & 0.457 & \\
\hline Maxillary implant vertical & 0.45 & 0.42 & -0.37 & 0.76 & -0.82 & 1.18 & -1.211 & \\
\hline \multirow[t]{2}{*}{ Pulatal descent } & 0.02 & 0.02 & -0.41 & 0.37 & -0.43 & 0.35 & -2.137 & $0.08^{*}$ \\
\hline & \multicolumn{8}{|c|}{ Group IV } \\
\hline Premaxillary implant horizontal & 0.24 & 0.41 & 0.47 & 0.47 & 0.23 & 0.73 & 0.541 & \\
\hline Premaxillary implant vertical & 0.24 & 0.23 & -0.22 & 0.20 & -0.46 & 0.43 & -1.859 & * \\
\hline Maxillary implant horizontal & 0.56 & 0.79 & 0.81 & 0.32 & 0.25 & 1.10 & 0.319 & \\
\hline Maxillary implant vertical & 0.30 & 0.02 & -0.29 & 0.41 & -0.59 & & & \\
\hline Palatal descent & 0.09 & 0.15 & -0.17 & 0.15 & -0.26 & 0.27 & -1.655 & \\
\hline
\end{tabular}

Statistics compiled for three animals per group.

*Also statistically significant from control group at 0.05 level.

* Also statistically significant from control group at 0.01 level.

**A Also statistically significant from control group at 0.005 level.

either forward or downward was antagonistic to the expected experimental result.

MAXILLARY SKELETAL ADAPTATIONS. The displacement of the maxillary complex associated with sutural growth was determined by measuring the translation of the maxillary implants relative to the implants in the anterior cranial base. A decrease in vertical displacement of the maxillary complex was noted in all but three of the experimental monkeys (Figs. 6 and 7, Table III). For example, the average vertical descent of the maxillary implants in Groups I and II was 35 to 50 per cent less than control level values (Table III). In Groups III and IV, which normally had less vertical development, further maxillary descent was inhibited and in some instances the maxilla was displaced slightly superiorly (Fig. 7, Table III). This reversal of growth pattern may have been related 
primarily to alterations in the vertical dimension, rather than to anteroposterior changes.

Vertical adaptations to the alterations in the oral environment were even more pronounced anteriorly. During the control period, this region of the maxillary arch normally moved horizontally with minimal but variable vertical movement. At the end of the experimental period, the premaxillary implant was displaced superiorly in all age groups to a greater extent than the maxillary implant (Table III, Figs. 6 and 7). The resultant differential displacement accentuated the normal counterclockwise rotation of the maxillary complex, and consequently the palatal plane was tipped upward anteriorly.

The experimental conditions affected the horizontal translation of the maxillary complex in all but animal IVc, but the expression of this effect varied among the animals. Five monkeys demonstrated a decreased forward displacement. In six animals increased displacement was noted. This variation may be related to the specific nature of the functional stresses placed against the maxillary arch in each animal.

MaXILlaRy DENTITIONAL Changes. The appliance had little effect on the buccal segments of the adolescent and adult animals because of the minimal migration normally occurring in the posterior teeth of these animals at these age levels and because of the total root surface involved. However, dentitional adaptations were evident in the younger animals. A reduction in the downward migration of the buccal segments relative to the location of the maxillary implants was observed in all three juvenile animals. On the other hand, reduced forward migration of the buccal segments was observed in the three infant monkeys and one juvenile monkey. This inhibition of tooth movement was consistent with the expected experimental result.

Adaptations in the anterior teeth were also evident in all age groups. The downward migration of the incisors increased and forward migration decreased. This compensatory tooth movement, which was similar to that of the lower incisors, was again an attempt to re-establish the occlusal plane.

overview. No single adaptive process could be isolated and identified as the sole cause of any effective alteration in maxillomandibular relationship at any age level. Rather, each resulting relationship was the composite of specific complementary (and occasionally antagonistic) adaptations throughout the craniofacial complex. The nature and extent of the adaptations varied with age and also among animals of the same age group. Mandibular adaptation was primarily skeletal in nature in the younger animals (Groups I and II), while compensatory dentitional movements became more significant with increased maturation. The primary effect of the experimental conditions on the middle face was on the extent and vector of growth of the skeletal components of the maxillary arch. This occurred at all age levels. Dentitional changes in the maxilla were primarily limited to the younger animals, for the buceal segments of the adolescent and adult groups were generally stable.

Microscopic growth and adaptation. The histologic appearance of the temporomandibular articulation of two experimental animals in each group was analyzed and compared with the control animals at that age level. The eight experimental 
animals had been killed 13 weeks after the beginning of the experimental period.

GROUP I. Generalized bone deposition was noted along the anterior border of the postglenoid spine and within the glenoid fossa. The posterior border of the spine, which is normally depository, showed evidence of bone deposition in animal II $b$ but was resorptive in animal I $c$. Areas of resorption could be identified along the lower two thirds of the posterior border. Resorptive activity was also noted on the articular eminence in both animals-in one at the crest of the eminence and in the other along the posterior slope.

No clear deviation in histologic structure was noted in the mandibular condyle. The condylar cartilage was proliferative in character but not to the extent that showed any increasing thickness when compared with control animals at this age level. Periosteal resorption and endosteal deposition were observed at the inscrtion of the lateral pterygoid muscle into the condylar head, a pattern that was also seen in control animals.

GRoUP II. Deposition of bone occurred along the posterior and upper anterior borders of the postglenoid spine, while surface resorptive responses were evident at the tip of the spine. The lining surface of the fossa was generally depository in nature, as was the conliguous articular eminence. In animal IIc, a localized area of periosteal surface resorption was observed in the lateral portion of the posterior slope of the eminence. This area was also noted in one control animal.

Of particular interest was the appearance of chondrocytes at the crest of the articular eminence deep to the fibrous articular surface. These cells usually resemble fibroblasts in this age group. Chondrocytes were observed in this region in one of the experimental animals and also, to a greater extent, in two of the control monkeys.

The morphology of the condylar structures of the experimental animals again could not be differentiated from that of the controls. Periosteal resorption and endosteal deposition were evident in the area of lateral pterygoid attachment.

GROUP III. Although the chondrocytes on the crest of the articular eminence showed hypertrophy in animal III $b$, a similar histologic appearance of hypertrophic chondrocytes was evident in four of the six control animals (Fig. 8). Animal III $c$ had little fibrocartilage proliferation on the eminence. The postglenoid spine was depository, both anteriorly and posteriorly, except for an area of resorption at the tip of the spine. No surface resorptive areas were observed within the fossa or along the eminence. The various mandibular components of the articulation, at this time interval, could not be differentiated from those of untreated specimens.

GRouP IV. The two experimental animals (IVb and IVc) and the sacrificed control (IVf) were young adult monkeys, and the three zones of the condylar eartilage were still identifiable. Fibrous articular tissue had not yet replaced the cartilage, as had already occurred in two of the other, older control animals.

The most noticeable histologic characteristic in Group IV was the appearance of cartilage cells in the deeper layers of the articular eminence and also a thickening of the fibrous articular covering on the eminence (Fig. 9). This was particularly apparent in animal IVc, but it was equally evident in one of the control animals. No evidence of pathologic change could be found in the experimental animals at any age level. 




Fig. 8. Hypertropic chondrocytes on the crest of the articular eminence (see arrows) in an adolescent experimental animal (IIIb). A similar occurrence was noted in several control animals of the same age level. (Hematoxylin and eosin stain. Magnification, $\times 16$.)

Fig. 9. Temporomandibular joint of an adult experimental animal. Note the thickening of the fibrous covering on the articular eminence (see arrows). A similar thickening of this surface was also observed in one control animal. (Hematoxylin and eosin stain. Magnification, $\times 8.1$

\section{Discussion}

Previous experimental studies on monkeys have shown that the production of controlled experimental disproportions, which alter the orofacial environment, can result in specific skeletal changes. Häupl and Psansky, ${ }^{3}$ Derichsweiler, ${ }^{5}$ and Joho, ${ }^{8}$ among others, have assumed that experimentally produced adaptations in the different skeletal elements involved were due to altered demands of the associated musculature. Yet, the so-called "functional nature" of orofacial adaptations is still essentially unclear, and few studies have been carried out that consider adaptations simultaneously occurring within the neuromuscular system.

In the present study, specific neuromuscular and skeletal adaptations result- 

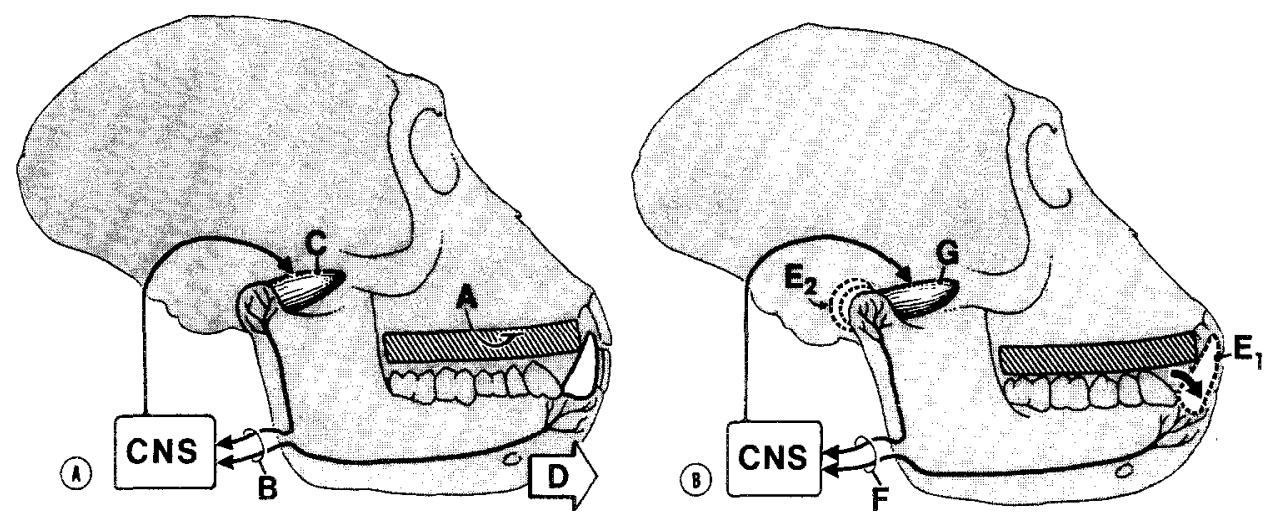

Fig. 10. Anteroposterior adaptations. A, Placement of the appliance. B, Alterations in exteroceptive and proprioceptive stimuli, as represented by receptors in the dentition and the temporomandibular joint, are transmitted to the central nervous system (CNS). $C$, this change in sensory stimuli eventually results in a complex pattern of altered neuromuscular function, represented schematically by contraction of the superior head of the lateral pterygoid muscle. $\mathbf{D}$, This results in a forward function position of the mandible.

The nature of the skeletal adaptations depends upon the maturation level of the animal. $\mathbf{E}_{1}$, One of the dentitional adaptations observed in the mature animals. $\mathbf{E}_{2}$, One of the skeletal changes occurring in the younger animals. $F$, Alterations in oral sensory stimuli again occur resulting in, $\mathbf{G}$, a decline in corresponding neuromuscular compensations and the development of more efficient muscle patterns.

ing from experimental modification of the oral environment have been deseribed in rhesus monkeys (Macaca mulatta) of varying maturational levels. An occlusal configuration was devised which altered oral sensory stimuli, subsequently inducing anterior positioning of the mandible during functional jaw movements. While the adaptive processes and responses outlined earlier are complex, two general types of adaptive responses are easily recognized: (1) adaptations of anteroposterior midface and mandibular dimensions and (2) adaptations in their vertical dimensions.

Anteroposterior adaptations. Closure of the mandible on the new occlusal configuration initially altered the exteroceptive and proprioceptive stimuli from the affected orofacial areas (Fig. 10). The appliance was designed so that the monkey had to learn to position his mandible anteriorly to produce effective jaw closurc. Existent patterns of functional musculoskcletal and ocelusal activity were interrupted and modifications in neuromuscular activity ensued.

DEVELOPMENT OF MODIFIED FUNCTIONAL PATTERNS. Specific modifications in functional activity were identified. A change in function was first reflected electromyographically by increased activity in the superficial head of the masseter muscle. The masseter in $M$. mulatta, as in man, is biomechanically suited for moderate protrusive movement. ${ }^{19}$ Decreased participation of the posterior portion of the temporal muscle was also noted. This alteration in muscle activity facilitated the sliding closure pattern of the mandible which was observed during the first part of the experimental period. 
Gradually the mandible was reflexively posilioned forward before closure to avoid appliance interference and occlusal trauma. Concurrently, the superior head of the lateral pterygoid muscle gradually increased in activity, with discharges evident both in functional movements and during maintenance of the postural position of the mandible (Fig. 10). The frequency of the tonic discharges increased in successive recordings, usually reaching a maximum at 4 to 8 weeks.

The inferior head of the lateral pterygoid was not specifically studied during the experimental phase of this project. However, occasional recordings from the inferior head did not reveal any evidence of hyperactivity or altered function in the inferior head of this muscle. Distinct patterns of activity were separately recorded from both heads, which indicated that a spread of activity from one head to the other during electromyographic recordings probably did not oceur.

In a study of normal lateral pterygoid function in Macaca mulatta, I have suggested that the two heads of this muscle are functionally independent. ${ }^{17}$ The superior head of the lateral pterygoid in the rhesus monkey is the only portion of this muscle which is electrically active during closing movements, while the inferior head with a downward orientation is active during opening movements. The latter head presumably assists in the translation of the head of the condyle anteriorly, inferiorly, and contralaterally during movements in which the condylar head is moved freely relative to the articular eminence.

I have postulated that a slight contraction of the superior head during closing movements may stabilize the condylar head and articular disc, keeping them synchronized with one another during movement against the articular eminence, especially during such functional movements as chewing and swallowing. He further suggests that an increased contraction of the superior head may move the articular disc, condylar head, and joint capsule anteriorly and slightly superiorly, presumably against the posterior and inferior surfaces of the articular eminence.

In the current study, the superior head of the lateral pterygoid appeared to assume an active role in the determination of anteroposterior mandibular position. The observed forward positioning of the mandible may have resulted from contractions in the superior head. These contractions may have anteriorly positioned (or rotated) and stabilized the articular dise and the head of the condyle along the articular eminence.

Findings from other experiments in our laboratory tend to support the suggestions that the superior head of the lateral pterygoid muscle may be a principal determinant of anteroposterior mandibular position. In an unpublished study of experimentally induced retrusive function of the mandible in monkeys, increased activity in the superior head of the lateral pterygoid was observed. Presumably, this increased activity reflected an attempt by this muscle to prevent posterior displacement of the mandibular condyle and articular disc during functional movements. However, in another study of increased vertical dimension in monkeys, ${ }^{20}$ no hyperactivity was observed in the superior head during functional movements after the mandible had been rotated inferiorly 2 to $15 \mathrm{~mm}$. with presumably little anteroposterior alteration in condylar position. Finally, 
in an unpublished study of monkeys which were experimentally rendered edentulous, the superior head of the lateral pterygoid became very hyperactive. In this instance, the superior head presumably functioned in stabilizing the condylar elements, perhaps in an attempt to regulate and maintain the anteroposterior and mediolateral orientation of the mandible. This increased activity of the superior head of the lateral pterygoid may have been necessary in the edentulous animals to compensate for the loss of the exteroceptive stimuli normally provided by the dentition.

In the experiments cited above and in the current study, increased activity in the superior head of the lateral pterygoid was usually associated with some change in the horizontal position of the mandible but was not observed in rotational or vertical alterations in functional position. This differential activity may indicate that the superior head of the lateral pterygoid not only stabilizes the articular disc and condylar head during normal closing movements but also may act as a posilioner of the condyle and articular disc along the articular surface of the temporal bone, thus assisting in the regulation and maintenance of the anteroposterior orientation of the mandible.

MECHANISMS OF MODIFIED FUNCTION. The establishment and maintenance of anteroposterior and mediolateral jaw relationships are dependent not only upon receptors in the temporomandibular joint and the musculature but also upon receptors in the periodontal ligament, the tongue, the palate, and other orofacial structures. Moyers ${ }^{18}$ states that centric relation and other jaw relationships are precisely defined only after the eruption of teeth. Sensory impulses from the periodontal receptors travel through the mesencephalic tract of the trigeminal nerve to subcortical or cortical levels where, together with stimuli from articular, muscular, and other oral receptors, these sensory impulses can influence the motor output to the masticatory muscles.

In the present study, when the mandible was elevated in closure, the mandibular canines initially contacted the occlusal onlay at an angle to the long axis of the tooth. The mandible was then guided anteriorly during closure by the canines sliding along the inclined planes of the appliance. The periodontal receptors have been shown to be more sensitive to lateral than axial stress. ${ }^{21,22}$ Presumably to avoid occlusal interferences, the stimuli from the periodontal mechanoreceptors and also from articular and muscular receptors may have prompted anterior displacement of the mandible. The increased activity in the superior head of the lateral pterygoid may be one manifestation of a reflex (first unconditioned and then conditioned) which assisted the animal in adapting to the experimental changes in the oral environment.

The anterior positioning of the mandible may also have been a secondary response to the alterations in oral volume caused by the appliance and the subsequent alteration in tongue posture. ${ }^{23,24}$ During the first few days of the experiment, the mandible was lowered, possibly to allow for the maintenance of the airway by altering the position of the tongue. As adaptive functional changes occurred, the tongue as well as the mandible may have been positioned anteriorly, not only to establish a more efficient functional position for mandibular movements but also to maintain an adequate oral volume for lingual function. 
CORRELATION OF NEUROMUSCULAR AND SKELETAL ADAPTATIONS. The progressive disappearance of modified neuromuseular patterns, such as those observed in the lateral pterygoid, must also be considered. The amount of activity in the superior head of this muscle may be directly or indirectly correlated to the gradual skeletal adaptations that resulted from the experimental procedures (Fig. 10).

At the termination of the experiments, it appeared as though most of the animals had skeletally adapted to the experimental changes. Cephalometrically, the mandibular condyles had regained their original anatomic orientation in the glenoid fossa of the temporal bone. The structural adjustments which permitted this relationship to be re-established were not localized in one area of the face but, rather, were a composite of many skeletal and dental adjustments throughout the craniofacial complex. The specific nature of these skeletal adaptations was directly related to the maturational level of the animal. For examplc, in the mandible, compensatory tooth movement was observed in the adolescent and adult animals while alterations in the amount and/or the direction of condylar growth was evident in the two younger age groups (Fig. 10). In this study it appeared that, as skeletal adaptations occurred, regardless of their specific nature, the need for compensatory muscle function was reduced.

This interrelationship of muscle function and structural adaptations can be further investigated by interrelating the current findings with those from other studies. By correlating these findings, the timing of the appearance and disappearance of altered functional patterns can be related to the rate and extent of skeletal and dental adaptations. In our initial protrusive study, ${ }^{10}$ on which the current study is partly based, six juvenile monkeys were subjected to a similar alteration in functional mandibular position for a 5-month period. Monthly growth increments were measured and, as in the present study, a statistically significant increase in the extent of growth within the mandibular condyle was noted. However, the rate of growth varied with the length of the time interval after appliance cementation. The increased growth rates of the experimental animals tended to occur during the first 3 months, with a peak occurring in the second month. At 4 months, however, the growth rate of the experimental animals was not significantly different from that of the controls.

In comparing the above results with those of the current study, it is important to note that the maximum rate of skeletal growth in these animals was during the second month. Maximum adaptive neuromuscular activity in the current study appeared just prior to or during this period. The decreasing rate of adaptive skeletal growth ean be assumed to indicate that structural balance had been restored by the fourth month. The activity of the superior head of the lateral pterygoid muscle was reduced by this time as well. However, the fact that the induced lateral pterygoid activity had not disappeared in all animals by the end of the experimental period also indicates that compensatory skeletal growth was not yet complete in some animals.

CORRELAtion OF NEUROMUSCULAR AND Microscopic Findings. Charlier ${ }^{25}$ and Petrovic and Stutzmann ${ }^{26}$ suggest that condylar growth may be dependent upon functional stimulation, especially from the lateral pterygoid muscle. Charlier ${ }^{25}$ has noted that the direction of growth of the mandibular condyle in man is coincident with the traction of the lateral pterygoid, whose posterior attachment 
is adjacent to the condylar cartilage. Charlier and Petrovic ${ }^{27}$ have reported that the condylar cartilage in rats does not appear to have an independent growth potential when isolated from its environmental structures. However, Vogel and Pignanelli, ${ }^{28}$ Charlier, ${ }^{25}$ and Charlier and associates ${ }^{29}$ have reported that the condylar cartilage ean react to stimulating functional forces with increased growth of the mandibular condyle. Anterior positioning of the mandible results in an increased growth of cells in the proliferative layer of the condylar cartilage.

Stöckli and Willert, ${ }^{9}$ in a histologic study of protrusive function in young monkeys, noted evidence of certain structural adaptations within the head of the condyle at specific time intervals. Increased proliferation of condylar cartilage and increased endochondral ossification were observed at $31 / 2$ and 7 weeks, respectively. However, no evidence of alterations in tissue response was reported at cither the 17 -week time interval or any succeeding intcrvals. Stöckli and Willert hypothesized that all the experimental animals passed through the same sequence of tissue response, but all evidence of adaptations was ultimately removed by normally occurring internal remodeling processes.

In the current study, the temporomandibular joints taken from the juvenile experimental animals did not present any histologic evidence of experimentally induced tissue response. However, the experimental period was of sufficient duration for an internal remodeling process similar to that described by Stöckli and Willert to have occurred, thus masking any evidence of transient adaptive responses. It is also possible that the adaptive processes were of such a nature that at no time interval could they be differentiated from normal growth processes. Enlow ${ }^{30}$ has shown that small vectoral changes during growth can result in altered structural relationships. Also, the adaptive processes may not necessarily involve differential increases in cartilage proliferation, endochondral ossification, and internal remodeling. If these processes all proceed at a relatively equal rate of increase, it would be difficult to differentiate between adaptive and normal growth mechanisms, if such differences do indeed exist.

Tlowever, if Stöckli and Willert have identified a specific adaptive mechanism at a microscopic level, this again correlates chronologically with the skeletal growth rates noted by Elgoyhen and co-workers ${ }^{10}$ and with the appearance and disappearance of the positioner function of the superior head of the lateral pterygoid muscle reported in the present study. The initial alteration in muscle function appeared to be directly associated with the experimentally induced changes in the oral environment. Neuromuscular function was disrupted and then reorganized to compensate for the alteration in structure. Then as skeletal balance was restored through specific structural adaptations, the neuromusculature began to re-establish more efficient functional patterns.

In the examples cited above, an increase in the condylar growth of young animals was related to the functional forward positioning of the mandible. Of course, this is only one method of skeletal adaptation. The specific nature and location of skeletal and dental adaptations varied according to the maturational level of the experimental animal.

In a similar study of mandibular displacement in the rhesus monkey, Hiniker and Ramfjord ${ }^{7}$ reported that the temporomandibular joints of the adult 


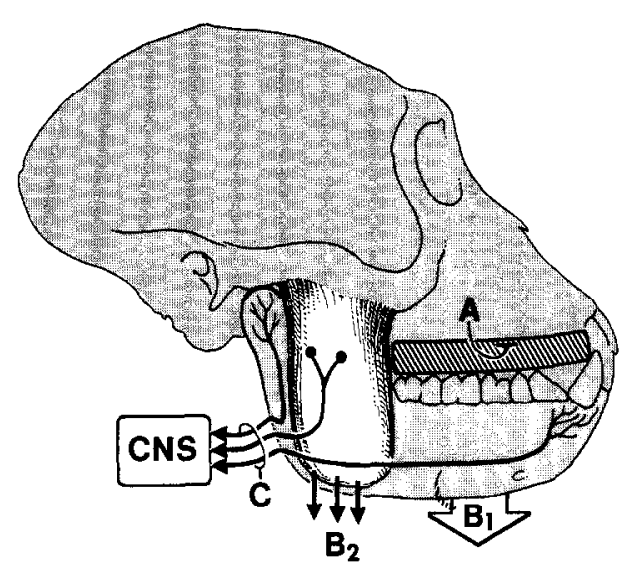

Fig. 11. Vertical adaptations. Placement of the appliance (A) results in, $\mathbf{B}_{1}$, a downward and slightly backward rotation of the mandible and, $B_{2}$, an immediate elogation of the association musculature. Oral sensation is again altered (C) as represented by sensory receptors in the dentition, the musculature, and the temporomandibular joint.

monkey were very stable and resistant to changes in occlusal relations and trauma. They stated that the microscopic adaptations in the joint were "insignificant, non-progressive, and possibly reversible without treatment." Similar findings were noted in the adult experimental animals in the present study. No evidence of alterations in remodeling patterns were noted, and no histopathologic findings were recorded.

The results of the microscopic portion of the current investigation are consistent with past studies which suggest that the histologic structure of the temporomandibular joint is stable and resistant to changes in function. These results, however, are also in agreement with studies which suggest that the temporomandibular joint is responsive to functional alterations. The principal factor, it is emphasized, is the age level of the experimental animal involved. A stimulus which may lead to adaptive changes at one particular time may be ineffective at a later stage of development.

Vertical adaptations. The placement of the appliance on the maxillary dentition not only caused a horizontal imbalance but also resulted in an immediate, effective increase in the structural height of the maxillary complex (Fig. 11). This altered the vertical maxillomandibular relationship by necessitating a downward and slightly backward rotation of the mandible. The mandibular rotation resulted in an elongation or stretching of some of the soft tissue attached between the mandible and superior craniofacial structures and in an effective shortening of others. Two soft-tissue responses to this repositioning of the bony elements were anticipated-(1) a "remodeling" of the associated connective tissue and (2) alterations in neuromuscular functions.

ALTERATIONS IN NEUROMUSCULAR FUNCTION. The effect of the vertical skeletal imbalance on the neuromusculature was expressed in two ways. Initially, the functional stresses placed upon the orofacial structures were reduced by hypo- 
and hyperactivity in selected muscle groups. For example, the hyperactivity observed in the suprahyoid muscle group presumably acted to depress the mandible. This change in mandibular position not only allowed for an adequate positioning of the tongue but also may have reduced occlusal trauma by preventing the lower teeth from erratically contacting the maxillary onlay. Importantly, however, these protective responses were of relatively short duration, since they disappeared within the first week as function became re-established.

Concurrent with the rapid emergence of those responses which apparently decreased occlusal stresses were other patterns characterized by increased musele activity and presumably increased occlusal stress. For example, increased elevator activity was observed in such patterns as swallowing and in random jaw movement. The lower jaw was often stabilized against the appliance before the initiation of a particular oral function. In contrast to the protective responses which disappeared early in the experiment, this increase in the frequency and duration of elevator function persisted to some degree throughout the duration of the experimental period.

The net effect of the vertical skeletal imbalance on the neuromusculature was quite different from the effect horizontally. In the anteroposterior dimension, positional reflexes were gradually learned, resulting primarily in a purposeful conditioned contraction of the superior head of the lateral pterygoid muscle. In contrast, the effective increase in height of the maxillary arch caused an immediate separation of the bony attachments of the clevator muscles which, for the most part, resulted in an elongation of their resting lengths (Fig. 11).

MECHANISMS OF NEUROMUSCULAR ADAPTATION. Boos, ${ }^{31}$ among others, has stated that any muscle or muscle group which has been elongated within physiologic limits will seek to re-establish functional homeostasis. Such adaptive mechanisms involve the following:

1. Elongation of the muscle fibers themselves. ${ }^{32}$

2. Establishment of altered neuromuscular feedback mechanisms. ${ }^{1}$

3. Migration of muscle attachments along bony surfaces. ${ }^{33,34}$

4. Occurrence of changed muscular dimensions due to displacement and rotation of the bony elements. This mechanism was specifically investigated in the current study, and the resultant growth and remodeling of the involved bony elements were analyzed. Because of the location of the attachments of the elevator musculature, the resultant skeletal adaptations could occur in the mandible, the maxilla, the cranial base, and the associated cranial areas. In this study, the first two areas were analyzed in detail. The growth of the maxillary complex (registered on the implants in the anterior cranial base) was most affected by the experimental conditions, as the normal downward displacement of the maxilla was reduced or inhibited in 75 per cent of the animals. Superior drifting of the mandibular molars was also slightly reduced, while the expression of the effect of the experiment on the maxillary dentition was variable. Vertical adaptations were less evident posteriorly. A decreased rate of superior condylar growth was noted in four of the six younger animals, but this finding may be also related to functional changes in the anteroposterior dimension.

Thus, evidence of a decrease in vertical dimension was observed as one of 
the sequelae of the appliance-related skeletal responses. While such a decrease may be related to muscle function, the effect upon other soft tissues must also be considered. As the bony elements were separated, there was also a passive stretching of portions of the associated connective tissues. If stresses were created within this connective tissue, this passive stretch of connective tissue may also be involved in the complex feedbacks of skeletal adaptations, especially since elevator muscle activity was not as hyperactive in the current experimental animals as in animals in which the alteration in vertical dimension was greater in extent. ${ }^{20}$ It can be considered that both muscle function and passive alteration of other types of soft tissue may be associated, directly or indirectly, with skeletal adaptation in instances of altered soft-tissue homeostasis.

General considerations. The division into vertical and anteroposterior components of the neuromuscular and skeletal adaptations observed in this study is artificial, since such functional changes proceed in an interdependent manner. Changes in facial height, depth, and width are closely interrelated, and alterations in one dimension or region of the craniofacial complex necessarily require a chain of concomitant changes in other areas.

Correlations have been observed in the timing of neuromuscular and skeletal responses, although in this study no direct cause-and-effect relationships could be established between muscle function and bone growth. However, a general sequence of adaptations can be postulated (Fig. 10). First, the exteroceptive and proprioceptive stimuli from the orofacial area were altered by the introduction of the appliance. Existent functional patterns were interrupted and reorganized. This, in turn, caused a change in maxillomandibular functional relationships. This change in functional pattern altered the orofacial environment in such a way that tissue structural adaptations resulted and an anatomic balance was eventually restored. As this occurred, neuromuscular compensation correspondingly declined and functionally more efficient patterns were developed.

Such an interrelationship may exist not only in an experimental situation but also during normal growth. Minute imbalances in structure or function may result in compensatory adaptive processes. It can be assumed that a complex feedback mechanism exists in the various skeletal and soft-tissue components of the craniofacial complex which serves to regulate and balance the interaction of muscle and bone.

\section{Summary}

The purpose of this study was to investigate the nature of intrinsic musculoskeletal adaptations resulting from experimental alteration of the orofacial environment. A new occlusal configuration was devised which modified oral sensory stimuli, subsequently prompting anterior positioning of the mandible of rhesus monkeys (Macaca mulatta) during functional jaw movements at four defined stages of maturation. Specific skeletal, dental, and neuromuscular adaptations were studied and interrelated by means of serial electromyography, serial cephalometric radiography with metallic implants, and microscopic analysis.

The study was divided into two time periods. During the 13-week control period, normal growth data were gathered from the four age groups. During the 
13-week experimental period, specific neuromuscular and skeletal alterations caused by the experimental conditions were identified. Postural activity in the muscles of mastication and presumably the postural position of the mandible were altered by the induced changes in the oral environment. The superior head of the lateral pterygoid gradually increased in activity, first during functional movements and then during the maintenance of mandibular postural position. The superior head appeared to function as a principal forward positioner of the mandible. This activity decreased or disappeared by the end of the experiment.

At the end of the experimental period, ten of the twelve experimental monkeys demonstrated an anteroposterior alteration in molar relationship. No single adaptive process could be isolated and identified as the sole cause of any effective alteration in maxillomandibular relationship at any age level. Rather, each resulting relationship was the composite of specific complementary (and occasionally antagonistic) adaptations throughout the craniofacial complex. Mandibular skeletal adaptations occurred primarily in the infant and juvenile animals in which the extent and direction of growth at the condyle were altered. Dentitional adjustments in the mandible were most notable in the adolescent and adult animals. In the nasomaxillary area a decrease in the vertical displacement of the maxillary complex was noted in all but three of the experimental animals. Horizontal displacement of the maxillary complex and the drift pattern of the maxillary dentition were also affected, but the expression of this effect was variable.

After 13 weeks, little histologic evidence of physiologic or pathologic responses to the induced protrusive function was evident in the sacrificed animals. These histologic findings werc consistent with past studies which suggest that the adult temporomandibular joint was stable and resistant while the growing articulation was responsive to functional changes.

The results of this study further indicated that a chronologic correlation existed between the occurrence and disappearance of altered neuromuscular function and the re-establishment of skeletal balance. As skeletal balance was restored through specific structural adaptations, the need for compensatory muscle function was reduced. Further, the nature and extent of the specific skeletal and dental adaptations depended upon the level of maturation of the animal.

The author wishes to acknowledge the help and advice of Donald H. Enlow, Robert E. Moyers, and Takayuki Kuroda. Technical assistance was provided by Ms. M. Christine McBride and editorial assistance by Ms. Ruth Bigio. Illustrations were prepared by Mr. William L. Brudon, Ms. Ruth Bigio, Mr. Gerald G. Davenport, and Mr. Edward E. Sayer.

\section{REFERENCES}

1. MeNamara, J. A., Jr.: Neuromuscular and skeletal adaptations to altered orofacial function. Monograph \#1, Craniofacial Growth Series, Ann Arbor, 1972, Center for Human Growth and Development, The University of Michigan.

2. Breitner, C.: Experimentelle Veränderung der mesiodistalen Beziehungen der oberen und unteren Zahnreihen, Z. Stomatol. 28: 343-356, 1930.

3. Häupl, K., and Psansky, R.: Experimentelle Untersuchungen Über Gelenktransformation bei Verwendung der Methoden der Funktionskieferorthopaedie, Dtseh. Zahn Mund Kieferheilkd. 6: 439-448, 1939. 
4. Hoffer, O., and Colico, G. L.: Le modificazioni dell'A.T.M. conseguenti a spostamento mesiale della mandibola, Rass. Int. Stomatol. Prat. 9: 27-40, Supp. 4, 1958.

5. Derichsweiler, H.: Experimentelle Tieruntersuchungen über Veränderungen des Kiefergelenkes bei Bisslageveränderung, Fortschr. Kieferorthop. 19: 30-44, 1958.

6. Baume, L. J., and Derichsweiler, H.: Is the condylar growth center responsive to orthodontic therapy? An experimental study in Macaca mulatta, Oral Surg. 14: 347-362, 1961.

7. Hiniker, J. J., and Ramfjord, S. P.: Anterior displacement of the mandible in adult rhesus monkeys, J. Prosthet. Dent. 16: 503-512, 1966.

8. Joho, J.-P.: Changes in form and size of the mandible in the orthopaedically treated Macaca irus (an experimental study), Trans. Europ. Orthod. Soc. 44: 161-173, 1968.

9. Stöckli, P. W., and Willert, H. G.: Tissue reactions in the temporomandibular joint resulting from anterior displacement of the mandible in the monkey, AM. J. ORTHOD. 60: 142-155, 1971.

10. Elgoyhen, J. C., Moyers, R. E., McNamara, J. A., Jr., and Riolo, M. L.: Craniofacial adaptation to protrusive function in young rhesus monkeys, AM. J. ORTHOD. 62: 469-480, 1972.

11. Ramfjord, S. P., and Fnlow, R. D.: Anterior displacement of the mandible in adult rhesus monkeys: long-term observations, J. Prosthet. Dent. 26: 517-511, 1971.

12. Hurme, V. O., and Van Wagenen, G.: Basic data on the emergence of permanent teeth in the rhesus monkey (Macaca mulatta), Proc. Am. Philo. Soc. 105: 105-140, 1961.

13. Rjörk, A.: The use of metallic implants in the study of facial growth in children: Method and application, Am. J. Phys. Anthropol. 29: 243-254, 1968.

14. Elgoyhen, J. C., Riolo, M. L., Graber, L. W., Moyers, R. E., and McNamara, J. A., Jr.: Craniofacial growth in juvenile Macaca mulatta: $\Lambda$ ecphalometrie study, Am. J. Phys. Anthropol. 36: 369-376, 1972.

15. Kuroda, T., and McNamara, J. A., Jx.: The effect of ketamine and phencycidine on muscle activity in non-human primates, Anesth. Analg. 51: 710-716, 1972.

16. MeNamara, J. A., Jr.: Restraint of monkeys for craniofacial research, J. Dent. Res. 52: 183, 1973.

17. MeNamara, J. A., Jr.: The independent functions of the two heads of the lateral pterygoid muscle, Am. J. Anat. 138: 197-206, 1973.

18. Moyers, R. E.: Some physiologic considerations of centric and other jaw relations, J. Prosthet. Dent. 6: 183-194, 1956.

19. Grant, P. G.: Biomechanical analyses of the masticatory muscles of the rhesus macaque (Macaca mulatta), Doctoral dissertation, University of California, Berkeley, 1972.

20. MeNamara, J. A., Jr.: Increasing vertical dimension in the growing face: An experimental study, AM. J. ORThoD. 64: 316, 1973.

21. Adler, P.: Sensibility of teeth to loads applied in different directions, J. Dent. Res. 26: 279-290, 1947.

22. Ness, A. R.: The mechanoreceptors of the rabbit mandibular incisor, J. Physiol. 126: $475.493,1954$.

23. Fish, S. F.: The respiratory associations of the rest position of the mandible, Br. Dent. J. 116: $149-159,1964$.

24. Bosma, J. F.: Human infant oral funetion. In Bosma, J. F. (editor): Symposium on oral sensation and proprioception, Springfield, Ill., 1967, Charles C Thomas, Publisher.

25. Charlier, J.-P.: Les facteurs mécaniques dans la croissance de l'are basal mandibulaire à la lumiere de l'analyse des caractères structuraux et des propriótós biologiques de cartilage condylien, Orthod. Franç. 38: 177-186, 1967.

26. Petrovic, M. A., and Stutzmann, J.: Le muscle ptérygoïdien externe et la croissance du condylo mandibulairc; rocherches experimentales chez le jeune rat, Orthod. Franç. 43: 271-285, 1962.

27. Charlier, J.-P., and Petrovic, A.: Recherches sur la mandibule de rat en culture d'organs: le cartilage condylien a-t-il un potentiel de croissance indépendent? Orthod. Franȩ. 38: $165-175,1967$.

28. Vogel, G., and Pignanelli, M.: Indagini istochimiche sull' articolazione T. M. del Macacus 
rhesus in corso di trattamento gnato-ortopedico, Rass. Int. Stomatol. Prat. 9: 46-50, Supp. 4, 1958.

29. Charlier, J.-P., Petrovic, A., and Herrmann-Stutzmann, J.: Effects of mandibular hyperpropulsion on the prechondroblastic zone of young rat condyle, AM. J. OnTIIOD. 55: 71-74, 1969.

30. Enlow, D. H.: The human face, New York, 1968, Hoeber Medical Division, Harper \& Row.

31. Bous, R. H.: Intermaxillary relation established by biling power, J. Am. Dent. Assoc. 27: 1192-1199, 1940.

32. Crawford, G. N. C.: An experimental study of muscle growth in the rabbit, J. Bone Joint Surg. 36B: 294-303, 1954.

33. Enlow, D. H.: Functions of the Haversian system, Am. J. Anat. 110: 269-306, 1962.

34. Hoyte, D. A. N., and Enlow, D. H.: Wolff's law and the problem of muscle attachment on resorptive surfaces of bone, Am. J. Phys. Anthropol. 24: 205-214, 1966.

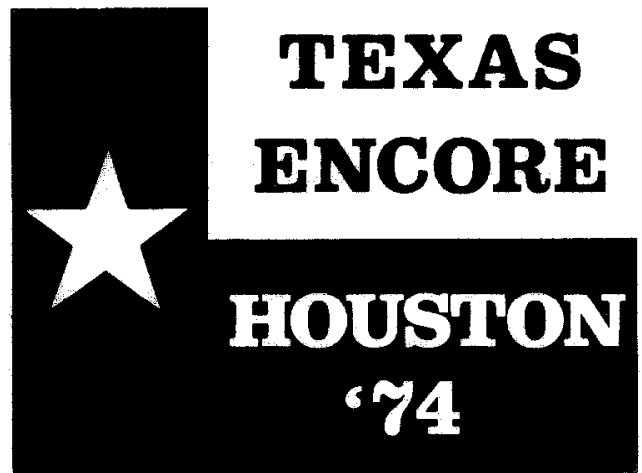

